\title{
Low Energy Cost Reciprocal Walking for the Adult Paraplegic
}

\author{
J. H. Patrick, F.R.C.S. ${ }^{1}$ and M. R. McClelland, F.R.C.S. ${ }^{2}$ \\ ${ }^{1}$ Consultant Orthopaedic Surgeon, and ${ }^{2}$ Research Fellow. Orthotic Research $\mathcal{E}$ \\ Locomotor Assessment Unit, The Robert fones $\mathcal{E}$ Agnes Hunt Orthopaedic Hospital, \\ Oswestry, Shropshire, U.K.
}

\section{Summary}

The hip guidance orthosis which allows paraplegic children to walk reciprocally has been further developed for adult traumatic paraplegics. Since December 1981, 11 adult complete paraplegics have walked using this device, designated a 'Parawalker'. Our understanding of the mechanics of this form of ambulation and our early work with functional electrical stimulation leave us hopeful of achieving a realistic goal for these patients.

Key words: Spinal injuries; Orthosis; Functional electrical stimulation.

\section{Introduction}

Walking for the adult paraplegic has always been a dream, but usually has been possible for low-level paraplegics only, often with a 'swing through' gait pattern. The difficulties engendered by lack of hip, abdominal and erector spinae musculature has made lateral and posterior instability ('fall-out') almost insuperable but for the fittest and most determined patients who have thoracic level complete paraplegia. Indeed our knowledge of the policy of spinal units in the United Kingdom shows that they recommend a wheelchair existence for dorsal level patients. Hoffer (1973) divided paraplegic ambulation into four functional levels:

1. Community ambulators: These patients walk indoors and outdoors for most of their activities and may need crutches or braces, or both. They use a wheelchair only for long trips out of the community.

2. Household ambulators: These patients walk only indoors and with apparatus. They are able to get in and out of the chair and bed with little if any assistance. They may use the wheel chair for some indoor activities at home and school, and for all activities in the community.

3. Non-functional ambulators: Walking for these patients is a therapy session at home, in school, or in the hospital. Afterwards they use their wheelchairs to get from place to place and to satisfy all their needs for transportation.

4. Non-ambulators: These patients are wheel-chair-bound but can usually transfer from chair to bed. 
Attempts are being made to stimulate electronically the muscles of the lower limb in sequence using microprocessor control systems, but so far the results allow for, at best, classification in Hoffer's Group 3. Most dorsal-level complete paraplegics using functional electrical stimulation (FES) can walk only on level surfaces in a laboratory situation, although we understand that Petrofsky in Ohio and Kralj in Yugoslavia have both had patients walking limited distances outdoors. The ORLAU experiment has been to develop further our expertise with the successful hip guidance orthosis (Rose, 1979) used for children with congenital paraplegia, so that it can be of benefit for adult traumatic cases. Our first adult incomplete patient walked (500 metres) in and out-doors in his orthosis (the Parawalker) in December 1981 proving the feasibility of the system. Since then we have treated 11 adult complete paraplegics, all of whom have walked. The case presented to the Athens' meeting of the International Medical Society of Paraplegia in 1982 is reported below in more detail (Patrick, 1982).

\section{Case report}

Mr A.E. now aged 20 years was admitted on 3 November 1981 to the West Midlands Spinal Injuries Centre having been involved in a motor cycle accident on 23 October 1981. He had sustained a complete paraplegia (motor and sensory level T4) because of a fracture dislocation of the 4th vertebra forwards on the 5 th thoracic vertebra. He had also sustained a fracture of the sternum and a laceration over the vertex of the scalp together with minor abrasions of both arms and knees and over the (left) hip. There was a slight kyphos in the upper dorsal spine, but no palpable defect and he had no voluntary muscle action below T4, nor sacral sparing. His previous history was unremarkable apart from an episode of Henoch-Schonlein purpura. After his accident he spent 2 days in Intensive Care because of low $\mathrm{PO}_{2}$ levels, although he was not ventilated artificially. His admission blood tests (full blood count, electrolytes and urea), together with a urine specimen for culture, were all normal. A vital capacity was 1300cc (lying on right side) and he had been catheterised.

Fourteen days after his accident he had an attempted reduction and instrumentation of his spinal dislocation to allow its stabilisation. The dorsal spinal column was dissected free at operation revealing a fracture of the lamina of T5 with a moderate kyphos. He then had a cardiac arrest and the operative procedure had to be abandoned. He completely recovered from this latter event.

Eight weeks after his accident he was allowed to sit up in bed and by nine and a half weeks from the fracture he was sitting in a wheelchair. He was not given the opportunity to try standing in calipers (this being the policy in our Spinal Injuries Unit since his level of paralysis would normally preclude a successful outcome) and mobilisation in a wheelchair was completed using our normal rehabilitation regime.

He was first considered for trial in the adult hip guidance orthosis (Parawalker) in April 1982, approximately 6 months from the time of his accident. He then had no neurological recovery whatsoever; was a competent wheelchair user and was obviously a fit, lightweight and a determined character. His mental reaction to his injury had always been impressively good; an IVP was normal, and apart from occasional urinary tract infections he was well, without any contractures, 


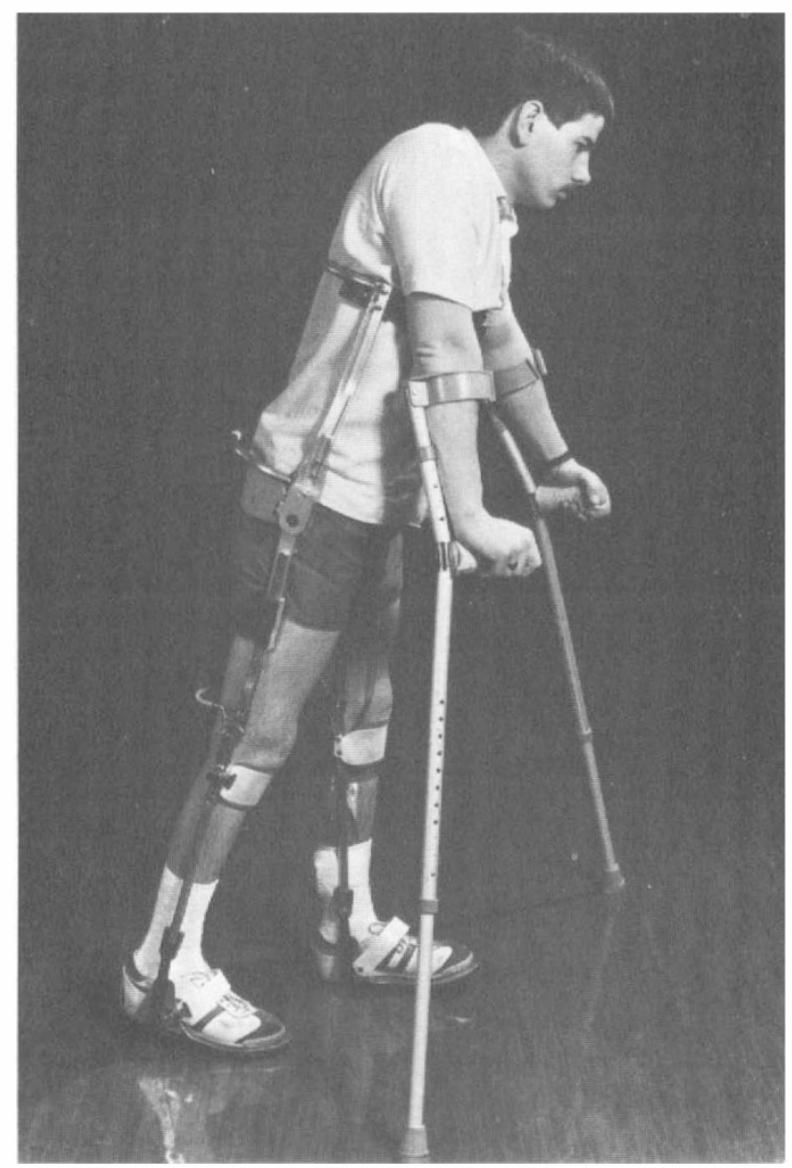

Figure 1. Patient A.E. in the 'Parawalker'.

although the radiological dorsal angulation at his fracture level had increased from 28 to 50 degrees over a 3-month period. He had unsustained clonic spasms in his legs (right more than left). On 5 July 1982 he was first fitted and tried in the Parawalker (Fig. 1). This first admission for walking practise took 11 days and he was then able to perform a short walk of 15 metres.

Over the next three months he was able to practise walking intermitently with his Parawalker. Practical difficulties limited the space available at home, so he was unable to perform well in the orthosis, although during admission periods to Oswestry he improved, with walking distances of more than 50 metres with crutches and Parawalker. At this stage a film was made for showing at the Athens meeting.

\section{Present research}

The combination of functional electrical stimulation (F.E.S.) and mechanical bracing to achieve ambulation in paraplegics had been suggested (Kralj \& Grobelnik, 1973) but it was felt that long-leg braces were 'heavy, difficult to 
doff and don and required tremendous physical effort to use'. The same conclusion was reached by Rose (1980) and efforts had been directed towards overcoming this view in our research laboratories. The hip guidance orthosis (the adult-use model is termed the Parawalker for distinction) has been the result of the ORLAU effort. Low energy expenditure, reciprocal (alternate) leg walking has become possible by the design of this orthosis (Rose, 1979). Paraplegia from most causes can be treated provided that severe contractures are not present. The essence of the design is to allow the mechanical advantage of gravity to swing the leg forward; extension of the stance hip being achieved by the transmission of the crutch/ground reaction on the contralateral side (Butler \& Major, 1984). The whole is given intrinsic stabilisation by the rigid orthotic exoskeleton and progression is achieved by inserting muscular generated forces through the arms into the system. Our earlier experience with this orthosis in children and the understanding of its function (Butler \& Major, 1984) suggested that Functional Electrical Stimulation would be of assistance for walking in the Parawalker if the abductors and extensors of the hip joint are stimulated. When building an orthosis of adult proportions it becomes difficult to maintain the same rigidity as is achieved in the smaller devices, especially in the region of the hip joint where by virtue of the design it is most flexible. This means that in single leg stance, deformation of the orthosis occurs in this area. The patient must do work with the ipsilateral crutch to control this deformation. Stimulation of hip abductor muscles resists abduction at the hip, and help to reduce the deformation of the orthosis and off load the crutch.

In November $1983 \mathrm{Mr}$ A.E. began an exercise routine of gluteal muscle stimulation for upwards of 1 hour daily. The objective of this was to build up the strength of these muscles which were markedly wasted some 2 years post paralysis. The skin over the electrode sites was cleaned using isopropyl alcohol. Two $10 \mathrm{~cm}$ diameter carbon impregnated rubber electrodes were used with 'Camjel' electrode jelly. The active electrode was placed on the buttock just below and medial to the posterior superior iliac spine and the indifferent electrode placed distal to this just above the buttock crease.

Within a month of starting the exercise regime there was dramatic improvement in Mr A.E.'s response to muscle stimulation. Work using FES shows that muscles can be brought back to full power in about 3 months (Kralj, 1973). At 2 months from the start of his exercise programme with A.E. standing in his Parawalker we showed that the addition of functional electrical stimulation of the gluteal muscles on the stance side increased the rigidity of the body/orthotic complex by resisting adduction at the hip. He was thus able to clear his swing leg more easily from the ground. The same stimulation also brought about extension of his hip, producing an effective 'electronic assist' to his orthosis.

\section{Equipment}

The electrical stimulators were supplied by Bio Medical Research Limited and were of two types. Both generated $0.2 \mathrm{~ms}$ rectangular waves at a frequency of $50 \mathrm{~Hz}$ and had an adjustable voltage output to a peak of 60 volts. In one stimulator the output could be triggered from a hand-held push-button while the other being intended for use as an exerciser, delivered 1 second trains of pulses every 2-3 seconds, these pulses being ramped on over approximately $300 \mathrm{~m}$ Secs. 


\section{Future work}

We are currently investigating here and in the University of Strathclyde incorporation of quadriceps stimulation to aid standing from a sitting position in the Parawalker. Quadriceps stimulation might also be used to further assist walking if we change the present bail-lock knee hinge to a freely hinged knee joint.

Since stimulation of a particular muscle group is required for less than half of the gait cycle (the orthosis is maintaining stability for the remainder), muscle fatigue is potentially avoided (Benton, 1981). The additional attraction of orthotic reciprocal ambulation is energy conservation. It is anticipated that the combination of FES and orthosis will result in a significant improvement in walking efficiency and will allow much less exhaustion, enhancing the treatment possibilities. We are as hopeful as any Research Department can ever be that our work has now reached a point where electronic stimulation allows an effective 'electronic-assist'. This may allow even household or community walking (Hoffer, 1973) for some of the adult paraplegics; bringing their 'dream' closer to reality. In a totally different sphere, we have already achieved this for congenital paraplegic children.

\section{Résumé}

L'appareil d'aide a la hanche (orthosis) qui permet aux enfants paraplegiques de marcher correctement a été developpéer d'advantage pour les adultes traumatiques paraplegiques.

Depuis Decembre 1981 onze adultes paraplegiques totales ont marchés en utilizant ce moyen qui s'appelle 'Parawalker'. Notre connaissance de la mecanique de cette forme de marche et nos premiers travaux sur la stimulation electrique fonctionnelle nous laissent plein d'espoir d'atteindre un but realiste pour ces malades.

\section{Zusammenfassung}

Diese mechanische Hilfe (Orthosis) fur das Huftgelenk, die den paraplegischen Kindern zu 'gehen' erlaubt, ist weiter entwickelt worden zu Gunsten der erwachsenen, traumatischen Paraplegier. Seit Dezember 1981 sind elf komplette Paraplegier zum 'Gehen' geholfen mittels dieses Gerates, 'Parawalker' genannt. Unser Verstandniss von dieser Art von Ambulation und unsere vorherigen Erfahrungen mit Funkionaler, elektrischer Stimulation gibt uns Hoffnung ein realistisches Ziel fur diese Patienten zu erreichen.

\section{References}

Benton LA, Baker LL, Bowman BR, Waters RL 1981 Functional Electrical StimulationA Practical Clinical Guide. 2nd ed. Ch. 5., P. 75 Rancho Los Amigos Rehabilitation Engineering Center, Downey, California.

Butler P, MAJOR RE 1984 Posthetics and Orthotics International 8:33-38.

Hoffer MM, Feiwell E, Perry J, Bonnett C 1973 Functional ambulation in patients with myelomeningocele. Journal of Bone and Joint Surgery (AM), 55-A:137-48.

KRALJ A, GREBELNIK S 1973 Functional electrical stimulation-a new hope for paraplegic patients? Bulletin of Prosthetics Research 10-20:75-102.

PATRICK JH 1982 Paper read at the International Medical Society of Paraplegia.

RosE GK 1979 The principles and practice of hip guidance articulations. Prosthetics and Orthotics International 3:37-43.

RosE GK 1980 Orthoses for the severely handicapped-rational or empirical choice. Physiotherapy 6:76-81. 